\title{
SOCIAL AND WORKING CONDITIONS OF OUR PARAPLEGICS
}

\author{
By J. V. Forner, M.D., D.Phys.Med., R. Miró, M.D., A. Manteiga, J. Suarez and \\ M. SERRA \\ Social Workers: A. Arana and M. D. BeJar \\ Departamento de Rehabilitación Ciudad Sanitaria, 'La Fe', Valencia
}

THE rehabilitation of the paraplegic patient is a complex process, requiring, in the first instance, a very specialised medical care aiming to restore the best possible physical and mental function, and in the second instance, services to resettle the disabled within the family, society and at work.

Both aspects of the rehabilitation process are interrelated, although unfortunately, do not always progress along parallel lines. If the physical and psychological condition of the patient is not adequate, it would not be possible to get employment after discharge. If the possibilities of employment after discharge are remote, the patient will lose interest in his rehabilitation. This lack of cooperation will impair the final result and will prolong his stay in hospital.

On the other hand, if the physical conditions are good on discharge from hospital, but the patients are not properly resettled in society and at work, they will feel useless and become anxious and depressed. This, in turn, may cause abandonment of their own physical state, leading to such complications as pressure sores, contractures and urinary infections.

The ideal situation is that the patient, after a good medical rehabilitation, is discharged from hospital with adequate provision of housing, social and working facilities, and is able to feel a useful member of the society.

Our main problem is that whereas from the medical point of view our results do not differ from those of other European Centres, as we strictly follow the methods settled by Sir Ludwig Guttmann at Stoke Mandeville Hospital, the social and industrial rehabilitation of our patients is far from satisfactory.

\section{Material}

We have surveyed the present situation of the first 200 patients treated in our Spinal Unit in Valencia by sending a questionnaire and, whenever possible, by personal interview.

Of these 200 patients, at least I4 had died and 26 did not answer our questionnaire and their present address was unknown, so we include the results of the remaining 160 cases. Of these, I09 were men and $5 \mathrm{I}$ were women.

The aetiology is varied although more than half the cases are traumatic $(57.5$ per cent), especially 'Road Traffic Accidents' (fig. I). About three-quarters of our patients are within working age (fig. 2). The low thoracic and cervical levels are more frequent (fig. 3). More than half the cases (64:4 per cent) are incomplete lesions, especially in the cervical and cauda equina levels. (We consider a lesion as incomplete when there is the slightest motor or sensory sparing.). More than a quarter $(26.8$ per cent) of our patients were admitted to our unit more than a year after the spinal lesion. Most of these chronic cases were admitted immediately 


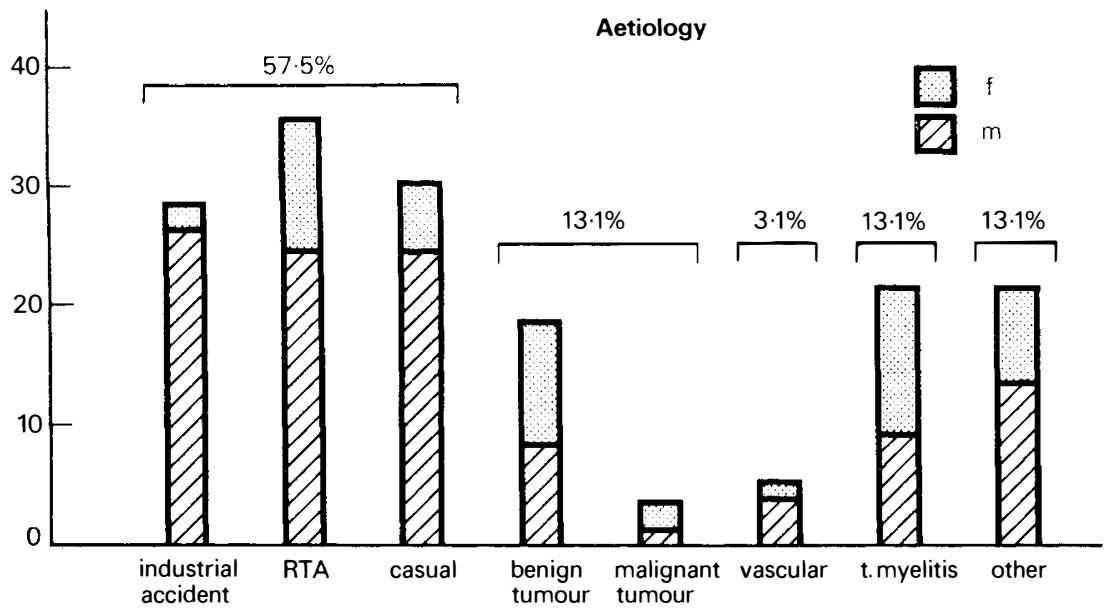

FIG. I

Aetiology.

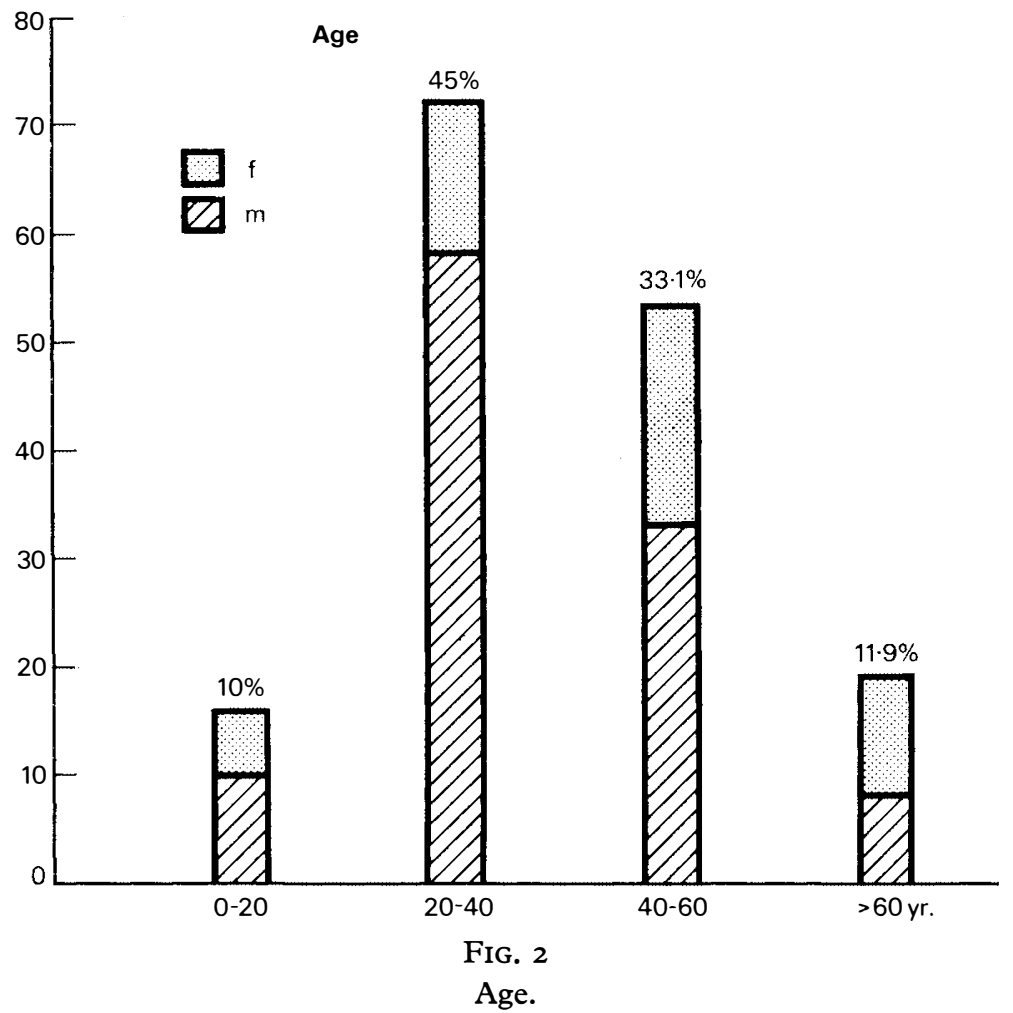




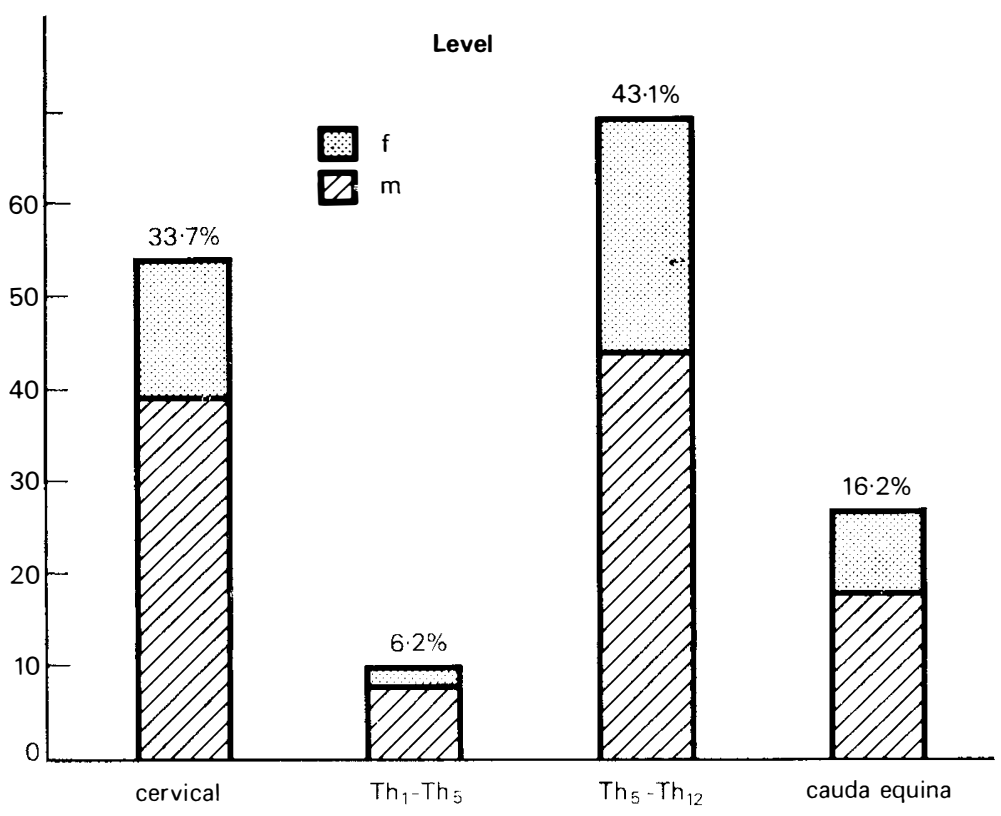

FIG. 3

Level of lesion.

after the opening of the Centre. Now we usually receive the patients soon after the accident.

About three-quarters of our patients $(76.9$ per cent) are independent for 'Activities of Daily Living' (fig. 4).

About two-thirds (65 per cent) of the patients use a wheelchair (fig. 5) (equal proportion of single and married cases). The great majority of our patients return to live with their families.

More than one-third $(38 \cdot 2$ per cent) of the patients return to inadequate housing with architectural barriers that limit their independence. More than half (58.I per cent) of the patients were unskilled workers. The women were generally housewives.

About three-quarters $(74 \cdot 2$ per cent) of our patients are illiterate or have a very low level of education (fig. 6). Only II 8 per cent of our patients earn wages. The rest have to rely upon a pension or familial earnings.

Almost two-thirds (64:3 per cent) of our patients are unemployed (fig. 7). We have only four cases with complete lesions that are working. The great majority of our patients are protected by National Insurance.

\section{Discussion}

After analysing the situation of our patients, one can see the very low number who are employed after discharge from hospital. This makes only II 8 per cent. If we exclude the housewives, there are 64.3 per cent of patients unemployed. Other authors in Spain give a percentage of 28 per cent of patients engaged in some type of work in the area of Barcelona, where there are better industrial facilities (Carabios, Aguilar et al., 1973). 


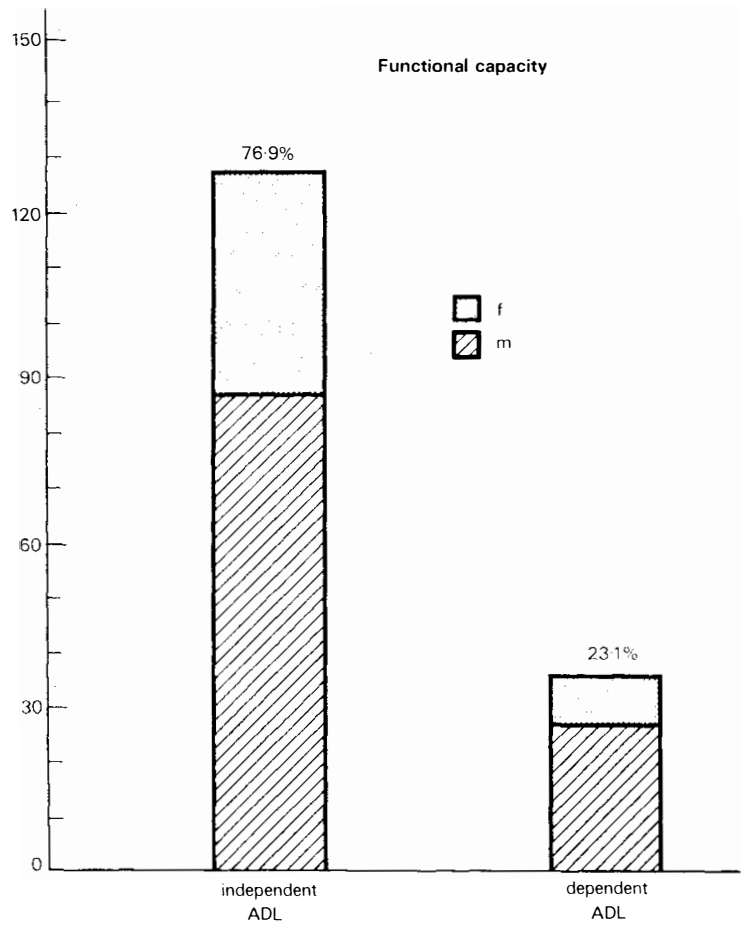

FIG. 4

Functional capacity.

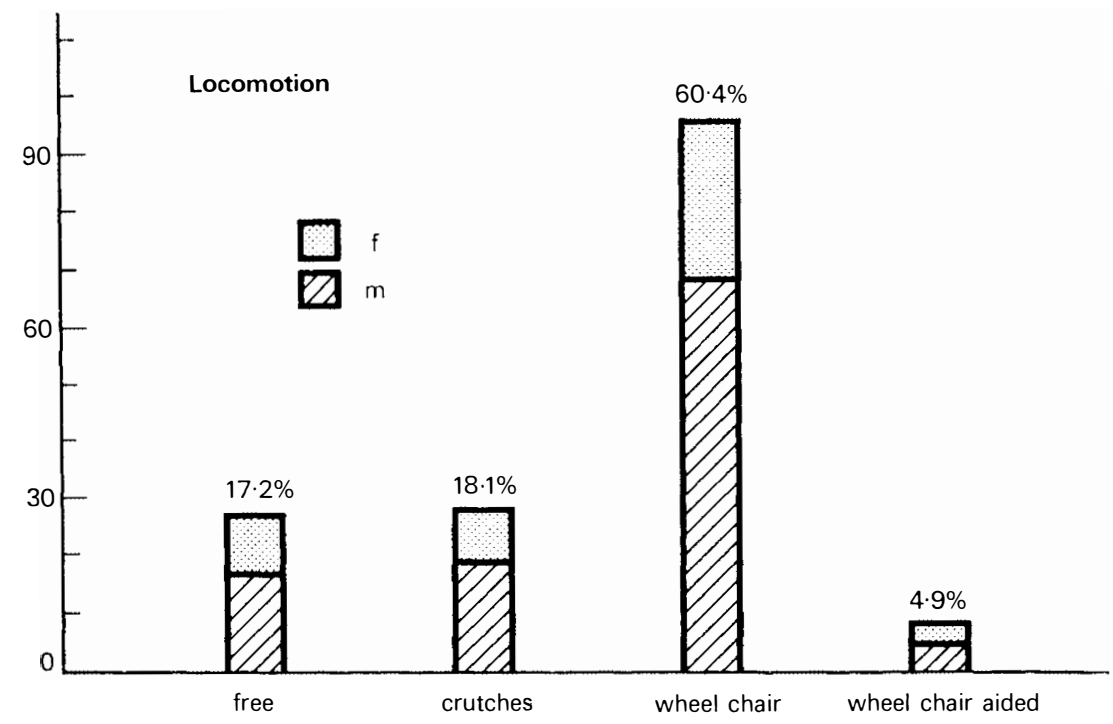

FIG. 5

Locomotion. 


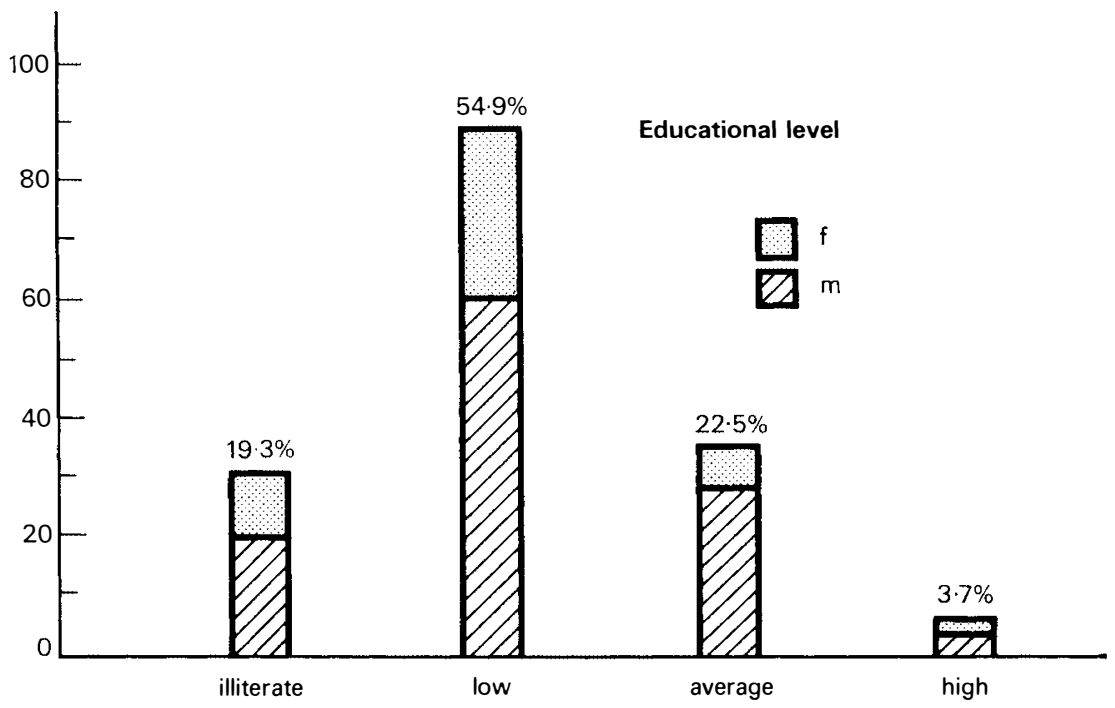

FIG. 6

Educational level.

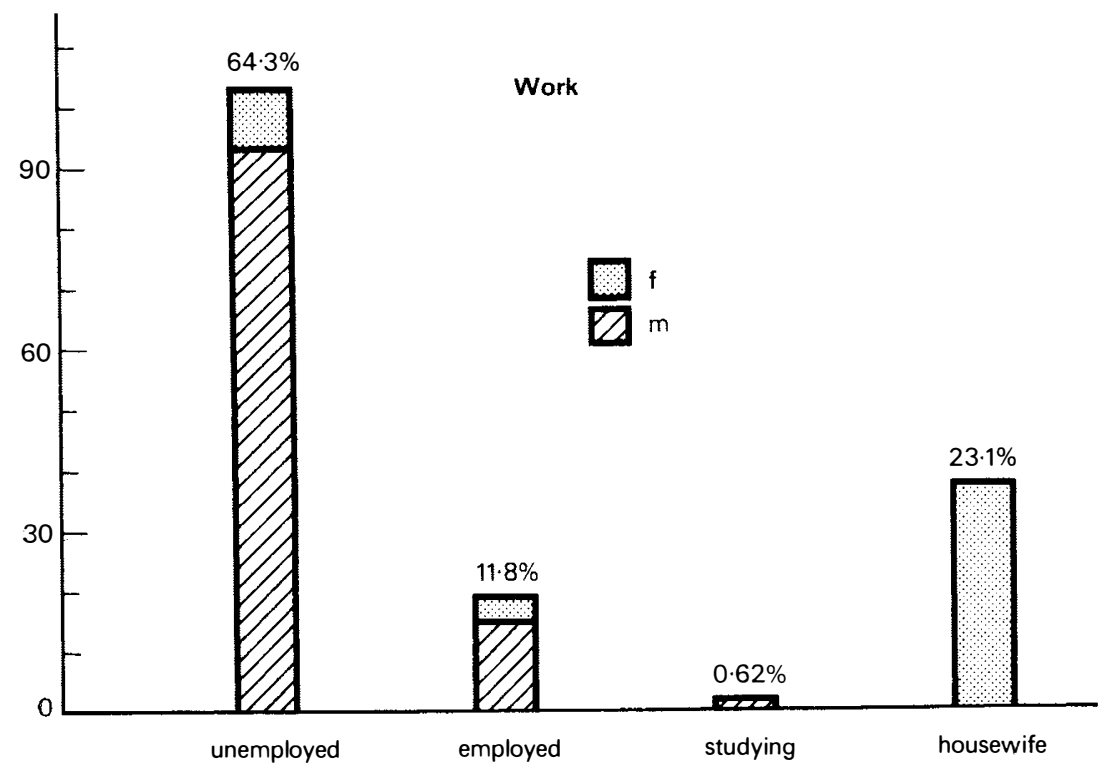

FIG. 7

Work. 
In Scotland, Johnson et al. (I972) report that 74 per cent of their paraplegics were unemployed, comparing unfavourably with the figures given by Guttman (I963) with only I 4.6 per cent unemployed and 85.4 per cent employed.

There may be several reasons for this low percentage of successful industrial rehabilitation. In the first instance, more than half of the patients (58. I per cent) were unskilled workers, or their work was non-sedentary. Then the low educational level, with 74.2 per cent of the patients illiterate or almost illiterate, makes the learning of a new occupation very difficult.

The existence of architectural barriers in their homes and in most factories and public buildings, make the social communication and travel to and from his post of work difficult for the paraplegic.

On the other hand, the Spanish employer is still reluctant to employ the disabled in the belief that their working efficiency will be low and absenteeism high. Last but not least we have to say that the social services in Spain are not yet well developed and most paraplegics have to find jobs for themselves.

To solve these problems and promote employment of the disabled, the Spanish authorities have passed on 22 August 1970 an act of law establishing the following measures:

(a) Create a 'Register of Disabled Persons' for persons whose disability is superior to 33 per cent.

(b) Provide facilities for Medical Rehabilitation, including the free prescription of prosthesis.

(c) Provide free vocational guidance and training to the registered disabled.

(d) Designation of certain posts in industry for disabled persons.

(e) Employers of more than 50 workers must employ a quota of 2 per cent disabled persons. There are exceptions in certain heavy industries.

(f) The earning of a salary will not affect the pension allowed.

(g) Allowances are made to employers that employ a number of disabled persons above the compulsory quota.

(h) Creation of centres for 'Sheltered Employment'.

(i) Admission of persons with severe disabilities to special 'pilot' centres.

We think that these measures will certainly benefit the persons with a lesser degree of disability but probably will not do very much to employ paraplegics considered as severely disabled. Nevertheless, it is a good step towards the employment of the disabled and with the opening of new special pilot Centres will help the industrial rehabilitation of our paraplegics.

\section{REFERENCES}

Carabias, A., Bernades, R. \& Maldonado, F. (I973). Rehabilitacion e integracion social de I4O paraplegicos de etiologia traumatica. Rehabilitatacion, 7, Fas. I.

Guttmann, SIR Ludwig (1973). Spinal Cord Injuries. Blackwell Scientific Publications, Oxford.

Johnson, G. S., Johnson, R. H. \& BowIE, G. (1972). Problems of social integration of paraplegics in Scotland. Paraplegia, 10, 126.

\section{Discussion}

Chairman: Professor A. Rossier. I think it was most encouraging to see the tremendous progress which has been accomplished by different countries to create new 
centres which are most attractive and in which each of us would like to spend some time, I believe. I would just like to open the discussion with one remark which will be a question. We have seen that on one of the slides shown by Dr Forner from the Toledo Centre, he quoted and showed circo-electric beds being utilised purposely for tetraplegics. I think it may be of interest to all of us to get your opinion on this type of bed which I personally consider contra-indicated in acute cervical cord patients.

DR J. Young (U.S.) We have tried these circo-electric beds. We have observed circo-electric syndromes which include pressure in the lower extremities because the patients like to watch the television, sometimes developing calcaneous sores because they fall asleep and press their heels against the iron bottom when the pillows slip. These are the obvious demerits and I would love to see some cine-radiography of the cervical spine as it flips over in the vertical axis. I think we would be horrified by what happens to the vertebrae as he goes over in the vertical position. So we decry the circoelectric bed.

MR P. HARRIs (G.B.). It has been fascinating to hear accounts of three new units in different countries and to see how they have been established and what they are meant to be doing. Just a couple of points: one is the financing and staffing of these Units especially Dr Forner's tremendous set-up. In our own country we do not have any new Unit as yet and the finance is a great problem. Secondly, the question of autonomy, because I do not feel that any of us can be autonomous, and what we do in our work requires cooperation from people in many different disciplines. We require close links, and I think some other people may agree, with general hospital facilities at many stages from the acute stage to the follow-up stage. Thirdly, the use of these Units in relation to education of their own staff in the Units and education of undergraduates in medicine and the paramedical workers.

DR RozIN (Israel). We are now in the process of constructing a spinal cord injury centre in Israel and I was quite surprised by the proportion of staff that I saw in Toledo. We thought that a proportion of one patient to $I \cdot 3$ nurses is the right proportion and not vice-versa as I saw in the slide. Secondly, there is a very big proportion of physicians there. I wonder who is turning the patient in the bed, the nurse or the doctor?

DR FORNER (Spain). First of all, we never use the circo-electric bed for turning the patient, we just wanted to try every kind of bed. The main bed we are going to use is a modified Stoke Mandeville-Egerton bed, but at the time when these slides were made we had not got them working yet. We use ordinary beds and are turning the patient by hand.

To answer Mr Harris: the hospital is financed by the National Insurance Social Security which is a national insurance supported by all workers in Spain, who pay something for insurance and are allowed to have every kind of treatment. The Centre has tried to be autonomous. I see now that it is not the completely right idea because we have to have our own laboratory, our own surgeon, our own orthopaedic and plastic surgeon, which I think is a lot of personnel and a mistake.

With regard to education, we have postgraduate training for six doctors, but, of course, most of the junior doctors go to other hospitals. In fact, of two of them one has gone already and one is going to open another Unit, so it will be the main source of doctors all around Spain.

I quite agree that it is a lot of doctors and even I was surprised when I saw in the advertisement that there were so many, and so I quite agree and it really supports my idea, either there are too many or we work very little.

DR BRUNo (Italy). I would like to ask Dr Mendoza what is his authority to make changes in the homes for tetraplegics or paraplegics discharged from hospital. He showed a slide when he presented a lot of problems, one of which are the modifications required in the home for discharged paraplegics and tetraplegics.

DR FoRNER (Spain) (answering for Dr Mendoza). Well, it is very difficult to get the money for the modifications but now there is new organisation created about $\mathrm{I} \frac{1}{2}$ or two years ago, which has the responsibility. I do not think it works very well as yet. The local authorities do not pay for this. 